\title{
The effects of testosterone replacement therapy in men with age-dependent hypogonadism on body composition, and serum levels of leptin, adiponectin, and C-reactive protein
}

\author{
Piotr Dudek, Jarosław Kozakowski®, Wojciech Zgliczyński \\ Department of Endocrinology, Medical Centrum of Postgraduate Studies, Bielański Hospital, Warsaw, Poland
}

\begin{abstract}
Introduction: Age-related hypogonadism in men leads to abnormal body composition development and overproduction of inflammatory cytokines, and thus has atherogenic and potentially cancer promoting effects. The aim of the study was to assess the effect of age-dependent testosterone deficiency replacement in men on body composition, serum leptin, adiponectin, and C-reactive protein levels. Material and methods: Men aged 50-65 years ( $56.0 \pm 5.7$, average \pm SD), with total testosterone levels $<4 \mathrm{ng} / \mathrm{mL}$, and clinical symptoms of hypogonadism were divided into two groups of 20 men and treated with testosterone ( $200 \mathrm{mg} /$ two weeks intramuscularly) or placebo during 12 months.

Results: Twelve months of treatment with testosterone led to body mass index (BMI) and fat mass (FM) decrease from $26.6 \pm 2.1$ to $26.1 \pm$ $1.8 \mathrm{~kg} / \mathrm{m}^{2}, \mathrm{p}<0.05$, and from $17.0 \pm 4.4$ to $15.6 \pm 4.0 \mathrm{~kg}, \mathrm{p}<0.05$, respectively. Body mass index and FM did not change in placebo-receiving subjects. Serum leptin and highly selective C-reactive protein (hsCRP) levels in testosterone group decreased from $6.2 \pm 1.4$ to $4.0 \pm 1.2$ $\mu \mathrm{g} / \mathrm{L}, \mathrm{p}<0.05$, and from $1.4 \pm 1.2$ to $1.0 \pm 1.0 \mathrm{mg} / \mathrm{L}, \mathrm{p}<0.05$ after 12 months, respectively. Adiponectin increased from $7.6 \pm 2.5 \mu \mathrm{g} / \mathrm{mL}$ to $9.4 \pm 2.8 \mu \mathrm{g} / \mathrm{mL}, \mathrm{p}<0.05$ in the same time. In the placebo group serum leptin, adiponectin, and hsCRP levels did not change significantly. Conclusions: Testosterone replacement in men with age-related hypogonadism causes a decrease in body mass index, fat mass, serum leptin, and C-reactive protein levels and increases serum adiponectin levels. (Endokrynol Pol 2020; 71 (5): 382-387)
\end{abstract}

Key words: aging male; hormonal supplementation; fat mass; cytokines

\section{Introduction}

Age-related hypogonadism in men leads to changes in body composition: a decrease in fat-free mass and gain of fat mass, dysfunction of many organs, and poor quality of life [1]. Increased fat mass results in overproduction of leptin and inflammatory cytokines and a state of chronic inflammation. Elevated leptin interferes with endothelial dysfunction, increases platelet adhesion, and stimulates the migration and proliferation of smooth muscle cells, and thus has atherogenic effects [2]. Moreover, hyperleptinaemia potentially promotes cancer development [3]. On the other hand, adiponectin - a cytokine with beneficial metabolic properties - exhibits vasoprotective effects [4,5]. C-reactive protein (CRP) is involved in atherosclerotic plaque formation and is considered as an independent risk marker for acute coronary incidents [6, 7].

The goal of the study was to assess the effect of age-dependent testosterone deficiency replacement in men on body composition, serum leptin, adiponectin, and C-reactive protein levels.

\section{Material and methods}

Forty men aged 50-65 years ( $56.0 \pm 5.7$, average \pm SD), who visited the outdoor clinic of the Endocrinology Department of the Medical Centrum for Postgraduate Studies (MCPS, Warsaw) due to clinical manifestations suggesting hypogonadism: erectile dysfunction, libido decline, hot flashes, abnormal sleep, and loss of self-confidence. In all subjects in two consecutive morning blood samples total testosterone levels $<4 \mathrm{ng} / \mathrm{mL}$ were found, and detailed clinical and laboratory studies were performed.

Exclusion criteria included:

- primary and secondary hypogonadism caused by hypothalamic-pituitary-testis axis diseases;

- taking medications that affect testosterone levels;

- obesity [body mass index (BMI) $\geq 30 \mathrm{~kg} / \mathrm{m}^{2}$ ];

- diseases: poorly controlled hypertension, coronary artery disease, heart failure, diabetes mellitus, serious liver disease, chronic renal disease, cancer, severe depression requiring pharmacological treatment;

- haematocrit $>54 \%$

- serum prostatic specific antigen (PSA) $>4 \mathrm{ng} / \mathrm{mL}$. 
Candidates were informed about the purpose of the study, and they gave their written consent. The subjects were divided into two groups of 20 men similar of age, height, weight, and clinical features of hypogonadism. One group was treated with testosterone and the other was considered as a control group. Treated individuals received testosterone enanthane (Testosteronum Prolongatum ${ }^{\circledR}$ Jelfa, ampoules $100 \mathrm{mg}$ in $1 \mathrm{~mL}$ ) at a dose of $200 \mathrm{mg}$ intramuscularly every two weeks. The control group was given a placebo (ampoules of $1 \mathrm{~mL}$ containing $0.9 \% \mathrm{NaCl}$, identical to the original preparation), also administered intramuscularly every two weeks.

The study project received a positive evaluation of the MCPS Bioethics Commission.

In each participant initially and after 3 and 12 months of treatment a clinical examination was performed with assessment of BMI. A blood sample was taken to determine total testosterone (TT) luteinising hormone (LH), follicle-stimulating hormone (FSH), leptin, and highly selective C-reactive protein (hs-CRP) levels. Blood samples for hormonal tests were taken fasting at 08.00 in the seventh day after administration of testosterone or placebo [8]. The body composition and the adiponectin levels were determined initially and after 12 months. To monitor the safety of testosterone treatment morphology, prostate-specific antigen (PSA) levels, palpate, and ultrasonographic prostatic gland (TRUS) examinations were performed in all subjects every six months.

\section{Assays}

Blood samples were taken from the elbow vein using TERUMO kits. Morphology: the assay was performed within four hours using a Sysmex SF-300 analyser (Sysmex Corp, Japan). Adiponectin, FSH, LH, hsCRP, leptin, and TT: approx. $9 \mathrm{~mL}$ for tubes without anticoagulant, after blood clotting within 30 to 60 minutes the blood was centrifuged for five minutes at approx. $4500 \mathrm{rpm}$. Part of the assays were performed using Hitachi 912, Elecsys 2010, and Immulite 2000 analysers on the day when the blood samples were taken. For the other assays, serum was stored in samples of $100-200 \mu \mathrm{L}$ at $-200^{\circ} \mathrm{C}$ according to the recommendations of kits' manufacturers.

Highly selective C-reactive protein was determined by immunoturbidimetry using a Hitachi 912 (Roche Diagnostics, Switzerland) analyser; PSA by immunoelectrochemiluminescence method (Elecsys 2010 Analyzer, Roche Diagnostics, Switzerland); FSH and LH by enzymatic immunoassay (Immulite 2000, dPC, USA); TT by the method of radioimmunoassay (RIA) using the TESTO-CT2 (Cis Bio International, France); adiponectin by RIA (Adiponectin RIA Kit, LINCO Research Inc., USA); and leptin by RIA (Human Leptin RIA Kit, LINCO Research Inc., USA).

Body composition separately in body regions was assessed by dual-energy X-ray absorptiometry method (DXA) using a General Electric DPX device. [9]

\section{Statistical analysis}

The results are presented as the mean value and standard deviation scores ( $x \pm \mathrm{SD}$, for numerical parameters), and the number and percentage of subjects that were examined in whom the characteristics occurred (for categorical parameters). Comparisons of the significance of changes before and after treatment were performed with Wilcox tests. Comparisons between groups on each visit were performed using the Mann-Whitney test. A p value of 0.05 was assumed to be statistically significant in all calculations. All calculations were performed using the R 3.3.1 statistical package.

\section{Results}

The baseline characteristics of participants are shown in Table 1.

\section{Effects of treatment on testosterone, LH, and FSH levels}

Testosterone supplementation caused an increase in serum total testosterone and a decrease in serum $\mathrm{LH}$ and FSH levels after 12 months: from $3.1 \pm 0.4$ (mean \pm SD) to $7.2 \pm 1.3 \mathrm{ng} / \mathrm{mL}$, from $4.0 \pm 2.2$ to $0.5 \pm 0.6 \mathrm{U} / \mathrm{L}$, and from $7.5 \pm 3.4$ to $0.9 \pm 1.0 \mathrm{U} / \mathrm{L}$, respectively, $\mathrm{p}<0.001$ in all cases. In the placebo group the levels of total testosterone, $\mathrm{LH}$, and FSH after 12 months were $3.3 \pm 0.5$ $\mathrm{ng} / \mathrm{mL}, 4.4 \pm 1.4 \mathrm{U} / \mathrm{L}$, and $6.3 \pm 1.8 \mathrm{U} / \mathrm{L}$, respectively; $\mathrm{p}<0.001$, compared to testosterone-treated subjects in all cases.

\section{Effects of treatment on body weight and body composition}

Treatment with testosterone led to weight loss from $78.3 \pm 6.3$ to $77.0 \pm 5.7 \mathrm{~kg}$ after 12 months, $\mathrm{p}<0.05$; there was no difference compared to the placebo group. At the same time the BMI in the treated group decreased from $26.6 \pm 2.1$ to $26.1 \pm 1.8 \mathrm{~kg} / \mathrm{m}^{2}, \mathrm{p}<0.05$; there was also no difference in comparison to the placebo group. After 12 months the fat mass (FM) in the treated group decreased from $17.0 \pm 4.4$ to $15.6 \pm 4.0 \mathrm{~kg}, \mathrm{p}<0.05$ and in the placebo group it increased from $19.1 \pm 4.9$

Table 1. Baseline characteristics of studied subjects

\begin{tabular}{lccc}
\hline & Testosterone $(\mathbf{n}=\mathbf{2 0})$ & Placebo $(\mathbf{n}=\mathbf{2 0})$ & $\mathbf{p}$ \\
\hline Age $[\mathrm{y}]$ & $56.9 \pm 5.7$ & $55.6 \pm 5.7$ & NS \\
\hline BMl $\left[\mathrm{kg} / \mathrm{m}^{2}\right]$ & $26.6 \pm 2.1$ & $26.5 \pm 2.6$ & NS \\
\hline BW $[\mathrm{kg}]$ & $78.3 \pm 6.3$ & $78.6 \pm 9.5$ & NS \\
\hline FM $[\mathrm{kg}]$ & $17.0 \pm 4.4$ & $19.1 \pm 4.9$ & $\mathrm{NS}$ \\
\hline FMt $[\mathrm{kg}]$ & $9.1 \pm 2.5$ & $10.1 \pm 3.0$ & NS \\
\hline Leptin $[\mu \mathrm{g} / \mathrm{L}]$ & $6.2 \pm 1.4$ & $6.0 \pm 2.4$ & NS \\
\hline Adiponectin $[\mu \mathrm{g} / \mathrm{mL}]$ & $7.6 \pm 2.5$ & $7.5 \pm 2.7$ & NS \\
\hline hsCRP $[\mathrm{mg} / \mathrm{L}]$ & $1.4 \pm 1.2$ & $1.5 \pm 1.2$ & NS \\
\hline
\end{tabular}

Testosterone — testosterone-treated group; Placebo — placebo-received group; $\mathrm{p}$ — statistical significance; BMI — body mass index; BW — body weight;

FM — fat mass; FMt — fat mass of the trunk; hsCRP — highly selective C-reactive protein; NS — not statistically significant 
Table 2. Serum leptin, adiponectin, and highly selective C-reactive protein (hsCRP) levels during the 12 months of the study in both groups

\begin{tabular}{lccccc}
\hline & \multirow{2}{*}{ Group } & \multicolumn{3}{c}{ Month } \\
\cline { 2 - 6 } & & $\mathbf{0}$ & $\mathbf{3}$ & $\mathbf{6}$ & $\mathbf{1 2}$ \\
\hline \multirow{2}{*}{ Leptin $[\mu \mathrm{g} / \mathrm{L}]$} & Testosterone & $6.2 \pm 1.4$ & $4.5 \pm 1.5^{\mathrm{a}}$ & $4.3 \pm 1.3^{\mathrm{a}}$ & $4.0 \pm 1.2^{\mathrm{a}, \mathrm{b}}$ \\
\cline { 2 - 5 } & Placebo & $6.0 \pm 2.4$ & $6.3 \pm 1.8$ & $7.1 \pm 2.1$ & $6.9 \pm 2.8$ \\
\hline \multirow{2}{*}{ Adiponectin $[\mu \mathrm{g} / \mathrm{mL}]$} & Testosterone & $7.6 \pm 2.5$ & - & - & $9.4 \pm 2.8^{\mathrm{a}, \mathrm{b}}$ \\
\cline { 2 - 5 } & Placebo & $7.5 \pm 2.7$ & - & - & $6.5 \pm 2.1$ \\
\hline \multirow{2}{*}{ hsCRP $[\mathrm{mg} / \mathrm{L}]$} & Testosterone & $1.4 \pm 1.2$ & $1.3 \pm 1.1$ & - & $1.0 \pm 1.0^{\mathrm{a}}$ \\
\cline { 2 - 5 } & Placebo & $1.5 \pm 1.2$ & $1.3 \pm 1.2$ & - & $1.6 \pm 1.3$ \\
\hline
\end{tabular}

${ }^{\text {a }} \mathrm{p}<0.05$, compared to initially; ${ }^{\mathrm{b}} \mathrm{p}=0.001$, compared to placebo group

to $19.9 \pm 5.2 \mathrm{~kg}, \mathrm{p}<0.05$. After 12 months the FM was lower in the testosterone-treated group compared to the placebo group, $\mathrm{p}=0.005$.

\section{Effects of treatment on serum leptin, adiponectin, and $C$-reactive protein}

Testosterone treatment resulted in a decrease in leptin levels already after three months from $6.2 \pm 1.4$ to $4.5 \pm 1.5 \mu \mathrm{g} / \mathrm{L}, \mathrm{p}<0.05$ and to $4.0 \pm 1.2 \mu \mathrm{g} / \mathrm{L}, \mathrm{p}<0.05$ after 12 months (decrease of $35 \%$ ). In the placebo group leptin levels after 12 months were $6.9 \pm 2.8 \mu \mathrm{g} / \mathrm{L}$; $\mathrm{p}<0.001$, compared to the testosterone-treated group. Adiponectin after 12 months of testosterone increased from $7.6 \pm 2.5 \mu \mathrm{g} / \mathrm{mL}$ to $9.4 \pm 2.8 \mu \mathrm{g} / \mathrm{mL}, \mathrm{p}<0.05$. In the placebo group adiponectin levels after 12 months were $6.5 \pm 2.1 \mu \mathrm{g} / \mathrm{mL} ; \mathrm{p}=0.001$, compared to the testosterone-treated group. Highly selective C-reactive protein levels in the testosterone-treated subjects de-

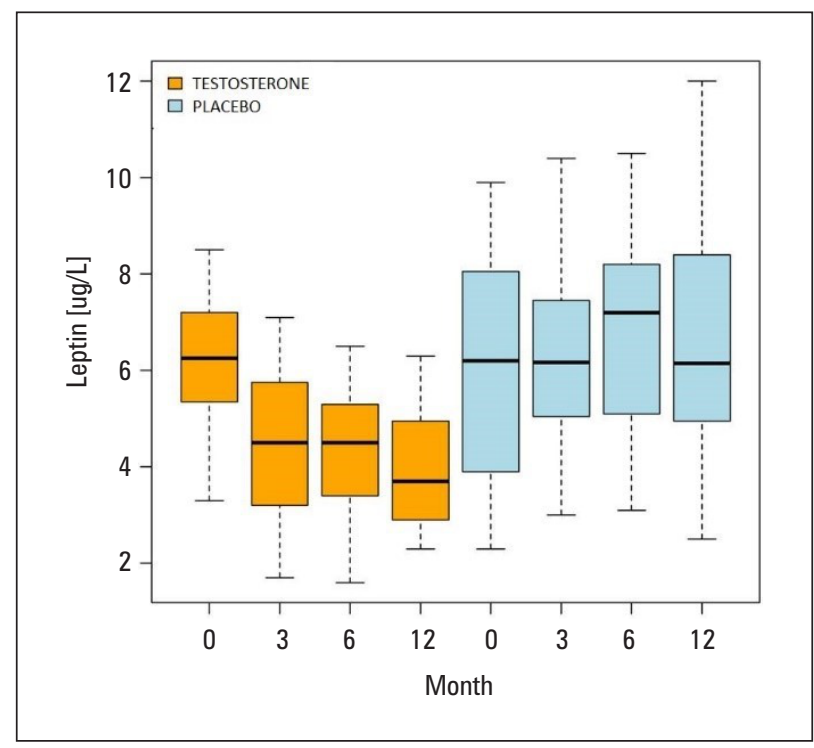

Figure 1. Leptin levels $[\mu \mathrm{g} / \mathrm{L}]$ in the testosterone-treated and placebo groups creased over a period of 12 months from $1.4 \pm 1.2$ to $1.0 \pm 1.0 \mathrm{mg} / \mathrm{L}, \mathrm{p}<0.05$. Changes in leptin, adiponectin, and hsCRP levels during 12 months in both groups are presented in Table 2, Figures 1 and 2.

\section{Correlations between serum leptin levels, adiponectin levels, and selected parameters}

The results of univariate analysis of regression between leptin and adiponectin levels and the selected parameters initially and after 12 months of treatment in both groups are shown in Table 3.

Baseline leptin levels in both groups positively correlated with body weight (BW), BMI, fat mass (FM), fat mass of the trunk (FMt), and CRP. After 12 months, in the testosterone-treated group leptin correlated positively only with FM. Baseline levels of adiponectin in both groups negatively correlated with BW, BMI, FM, FMt, CRP, and leptin (Fig. 3). After 12 months, in the

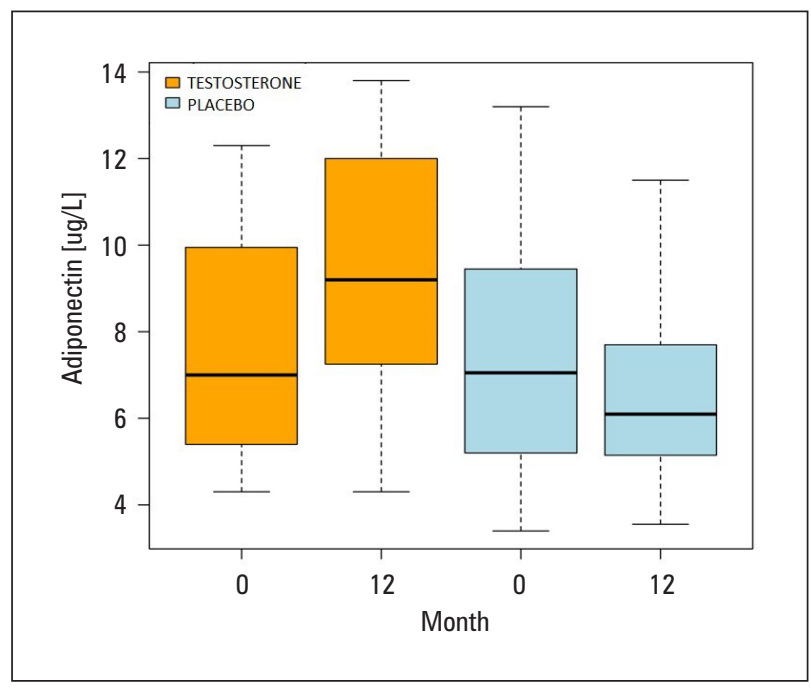

Figure 2. Adiponectin levels $[\mu \mathrm{g} / \mathrm{mL}]$ in the testosterone-treated and placebo groups 
Table 3. Correlations between serum leptin and adiponectin levels and the selected parameters before and after 12 months in the testosterone-treated and placebo groups

\begin{tabular}{lcccccccc}
\hline & \multicolumn{3}{c}{ Month $\mathbf{0}$} & \multicolumn{2}{c}{ Month 12 } \\
\cline { 2 - 10 } & \multicolumn{2}{c}{ Testosterone } & Placebo & Testosterone & \multicolumn{2}{c}{ Placebo } \\
\cline { 2 - 10 } & $\mathbf{W}$ & $\mathbf{p}$ & $\mathbf{W}$ & $\mathbf{p}$ & $\mathbf{W}$ & $\mathbf{p}$ & $\mathbf{W}$ & $\mathbf{p}$ \\
\hline L vs. BMI & 0.526 & 0.017 & 0.739 & $<0.01$ & 0.259 & NS & 0.670 & 0.001 \\
\hline L vs. FM & 0.530 & 0.016 & 0.839 & $<0.01$ & 0.523 & 0.018 & 0.762 & $<0.01$ \\
\hline L vs. FMt & 0.555 & 0.011 & 0.686 & 0.001 & 0.669 & 0.001 & 0.629 & 0.004 \\
\hline L vs. BW & & & 0.608 & 0.004 & & & 0.585 & 0.007 \\
\hline L vs. CRP & 0.456 & 0.043 & 0.776 & $<0.01$ & 0.238 & NS & 0.608 & 0.004 \\
\hline A vs. L & -0.548 & 0.012 & -0.587 & 0.007 & -0.333 & NS & -0.369 & NS \\
\hline A vs. BMI & -0.668 & 0.01 & -0.660 & 0.002 & -0.674 & 0.001 & -0.671 & 0.001 \\
\hline A vs. FM & -0.411 & 0.071 & -0.473 & 0.035 & -0.395 & 0.085 & -0.466 & 0.039 \\
\hline A vs. FMt & -0.350 & NS & -0.381 & NS & -0.227 & NS & -0.284 & NS \\
\hline A vs. CRP & -0.549 & 0.012 & -0.779 & $<0.01$ & 0.799 & $<0.01$ & -0.669 & 0.001 \\
\hline
\end{tabular}

Testosterone - testosterone-treated group; Placebo — placebo group; W — Spearman's rank correlation coefficient; $p$ — value of significance level; $L$ - leptin; $\mathrm{A}$ — adiponectin; BMI — body mass index; FM — fat mass; FMt — fat mass of the trunk; BW — body weight; CRP — highly selective C-reactive protein; NS - not statistically significant

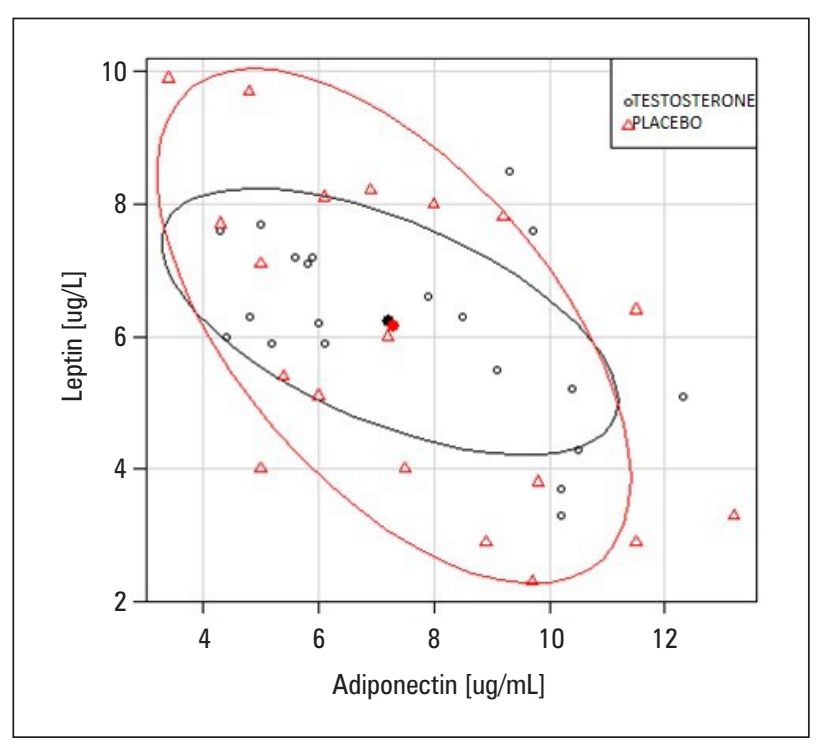

Figure 3. Correlation between adiponectin and leptin before treatment in both groups

testosterone group the negative correlation was maintained in relation to BW, BMI, and CRP.

\section{Safety of treatment}

None of the subjects experienced adverse impact of testosterone or placebo on the course of co-existing diseases. Prostate-specific antigen levels increased within 12 months in the testosterone-treated and the placebo group: from $0.9 \pm 0.4$ to $1.2 \pm 0.5 \mathrm{ng} / \mathrm{mL}, \mathrm{p}<0.05$, and from $0.9 \pm 0.5$ to $1.1 \pm 0.5 \mathrm{ng} / \mathrm{mL}, \mathrm{p}<0.05$, respectively. Differences between the groups were not statistically significant at any time point. The haematocrit increased at the same time in both groups; however, in the testosterone group this increase was higher (from $44.6 \pm 2.7$ to $48.2 \pm 2.5 \%, \mathrm{p}<0.05)$ and the differences between the two groups at 12 months were significant (placebo group $44.7 \pm 3.0 \%, \mathrm{p}<0.001)$.

\section{Discussion}

A decrease in testosterone secretion significantly contributes to changes in the body composition of the aging male [10]. Fat-free mass decreases and enhancement of fat mass is observed. Adipose tissue starts to produce proinflammatory cytokines. Serum leptin and CRP are higher, and adiponectin levels decrease [11]. Lowering of the energy expenditure and insulin sensitivity associated with obesity lead to metabolic syndrome development and augmentation of cardiovascular risk. In our study we demonstrate that 12-month testosterone supplementation reduces fat mass, significantly lowers leptin levels, and increases adiponectin levels.

After three months of therapy we found a significant reduction in serum leptin levels, and this trend was continued in the following months. In contrast, during the 12 months leptin levels in the placebo group increased by $15 \%$. Similar results were obtained by Luukkaa et al. in young healthy males who used $200 \mathrm{mg}$ of testosterone intramuscularly once weekly for 12 months as a contraceptive [12]. After three months of testosterone withdrawal leptin levels returned to baseline, which may indicate direct inhibitory effects of testosterone on leptin production. We showed at baseline a positive correlation between leptin levels and body weight, BMI, and fat mass in our subjects. Similarly to others $[13,14]$, 
we did not find a correlation between testosterone and leptin levels. The mechanisms of the impact of testosterone on the leptin levels are not entirely understood. An indirect effect associated with fat mass reduction seems to be obvious. However, also direct effects cannot be ruled out, as indicated in our work by the decrease in leptin levels after three months of therapy. Wabitsch et al. in in vitro studies on human adipocytes showed an inhibitory effect of testosterone on leptin synthesis and mRNA [15].

It is well known that high leptin levels increase cardiometabolic risk and adversely affect the structure of blood vessels, which can lead to hypertension and atherosclerosis progression [16]. A recent meta-analysis showed that high leptin levels may be considered as an independent marker of increased risk of myocardial infarction [17]. Moreover, the relationship between hyperleptinaemia and development of some cancers was proven [18]. Hence, it must be assumed that the decrease in leptin levels in older men during testosterone supplementation reduces the risk of insulin resistance, type 2 diabetes, cardiovascular diseases, and the development of certain cancers.

In our study we demonstrate a significant increase in adiponectin levels - over $23 \%$ after 12 months of therapy with testosterone. Adiponectin is known to exhibit anti-inflammatory properties and correlates with a decline in fat mass and insulin resistance. Page et al. [19] and Frederiksen et al. [20] observed a decrease in adiponectin levels after testosterone treatment. Our study is probably the first to demonstrate an increase in the adiponectin levels following supplementation of testosterone deficiency. The mechanism of this process is complex and involves the direct impact of testosterone on the production of adiponectin and is partly a consequence of the fat mass decrease.

Treatment with testosterone did not significantly affect hsCRP levels when compared to placebo in our study, although we noted a decrease in protein levels by $7 \%$ after three months and by $28 \%$ after 12 months among treated patients. Decrease in hsCRP levels may be a consequence of a fall of fat mass resulting in lower interleukin 6 production, which is considered as responsible for stimulating CRP synthesis.

We did not observe any serious adverse effects of testosterone therapy. Prostate-specific antigen and haematocrit levels increased in the treatment group, but this was an expected effect and did not result in the exclusion of any patients from the study. The increase in PSA levels occurred in both groups, although only among users of testosterone was it statistically significant. The increase can be explained by the physiological process of increasing prostate volume associated with male ageing. It is also well known that testosterone treatment may cause a slight increase in PSA levels and prostate gland volume [21]. In our study we did not observe an increase in PSA above $1 \mathrm{mg} /$ year or values above $4 \mathrm{mg} / \mathrm{L}$.

The limitation of the study is a small group of subjects, which reduces the statistical value of obtained results. However, our work can be used for further, more extensive research on hormonal conditioning in aging males.

\section{Conclusions}

Testosterone replacement in men with age-related hypogonadism causes a decrease in BMI, fat mass, serum leptin, and CRP levels and increases serum adiponectin levels.

\section{References}

1. Stanworth RD, Jones TH. Testosterone for the aging male; current evidence and recommended practice. Clin Interv Aging. 2008; 3(1): 25-44, doi: 10.2147/cia.s190, indexed in Pubmed: 18488876

2. Payne GA, Tune JD, Knudson JD. Leptin-induced endothelial dysfunction: a target for therapeutic interventions. Curr Pharm Des. 2014; 20(4): 603-608, doi: 10.2174/13816128113199990017, indexed in Pubmed: 23688011.

3. Jardé T, Perrier S, Vasson MP, et al. Molecular mechanisms of leptin and adiponectin in breast cancer. Eur J Cancer. 2011; 47(1): 33-43, doi: 10.1016/j.ejca.2010.09.005, indexed in Pubmed: 2088933.

4. Ouchi N, Ohishi M, Kihara S, et al. Association of hypoadiponectinemia with impaired vasoreactivity. Hypertension. 2003; 42(3): 231-234, doi: 10.1161/01.HYP.0000083488.67550.B8, indexed in Pubmed: 12860835.

5. Kumada M, Kihara S, Sumitsuji S, et al. Osaka CAD Study Group. Coronary artery disease. Association of hypoadiponectinemia with coronary artery disease in men. Arterioscler Thromb Vasc Biol. 2003; 23(1): 85-89, doi: 10.1161/01.atv.0000048856.22331.50, indexed in Pubmed: 12524229.

6. Calabro P, Chang DW, Willerson JT, et al. Release of C-reactive protein in response to inflammatory cytokines by human adipocytes: linking obesity to vascular inflammation. J Am Coll Cardiol. 2005; 46(6): 1112-1113, doi: 10.1016/j.jacc.2005.06.017, indexed in Pubmed: 16168299.

7. Ridker PM, Hennekens $\mathrm{CH}$, Buring JE, et al. C-reactive protein and other markers of inflammation in the prediction of cardiovascular disease in women. N Engl J Med. 2000; 342(12): 836-843, doi: 10.1056/NEJM200003233421202, indexed in Pubmed: 10733371.

8. Diver MJ, Imtiaz KE, Ahmad AM, et al. Diurnal rhythms of serum total, free and bioavailable testosterone and of SHBG in middle-aged men compared with those in young men. Clin Endocrinol (Oxf). 2003; 58(6): 710-717, doi: 10.1046/j.1365-2265.2003.01772.x, indexed in Pubmed: 12780747 .

9. Mazess RB, Barden HS, Bisek JP, et al. Dual-energy x-ray absorptiometry for total-body and regional bone-mineral and soft-tissue composition. Am J Clin Nutr. 1990; 51(6): 1106-1112, doi: 10.1093/ajcn/51.6.1106, indexed in Pubmed: 2349926.

10. Finkelstein JS, Lee H, Burnett-Bowie SAM, et al. Gonadal steroids and body composition, strength, and sexual function in men. N Engl J Med. 2013; 369(11): 1011-1022, doi: 10.1056/NEJMoa1206168, indexed in Pubmed: 24024838.

11. Galic S, Oakhill JS, Steinberg GR. Adipose tissue as an endocrine organ. Mol Cell Endocrinol. 2010; 316(2): 129-139, doi: 10.1016/j.mce.2009.08.018, indexed in Pubmed: 19723556.

12. Luukkaa V, Pesonen U, Huhtaniemi I, et al. Inverse correlation between serum testosterone and leptin in men. J Clin Endocrinol Metab. 1998; 83(9): 3243-3246, doi: 10.1210/jcem.83.9.5134, indexed in Pubmed: 9745436.

13. Van Den Saffele JK, Goemaere S, De Bacquer D, et al. Serum leptin levels in healthy ageing men: are decreased serum testosterone and increased adiposity in elderly men the consequence of leptin deficiency? Clin Endocrinol (Oxf). 1999; 51(1): 81-88, doi: 10.1046/j.1365-2265.1999.0074 1.x, indexed in Pubmed: 10468969.

14. Haffner SM, Miettinen H, Karhapää P, et al. Leptin concentrations, sex hormones, and cortisol in nondiabetic men. J Clin Endocrinol Metab. 1997; 82(6): 1807-1809, doi: 10.1210/jcem.82.6.3978, indexed in Pubmed: 9177386. 
15. Wabitsch M, Blum WF, Muche R, et al. Contribution of androgens to the gender difference in leptin production in obese children and adolescents. J Clin Invest. 1997; 100(4): 808-813, doi: 10.1172/JCI119595, indexed in Pubmed: 9259579.

16. Ghantous CM, Azrak Z, Hanache S, et al. Differential Role of Leptin and Adiponectin in Cardiovascular System. Int J Endocrinol. 2015; 2015: 534320, doi: 10.1155/2015/534320, indexed in Pubmed: 26064110.

17. Srikanthan K, Feyh A, Visweshwar H, et al. Systematic Review of Metabolic Syndrome Biomarkers: A Panel for Early Detection, Management, and Risk Stratification in the West Virginian Population. Int J Med Sci. 2016; 13(1): 25-38, doi: 10.7150/ijms.13800, indexed in Pubmed: 26816492

18. Booth A, Magnuson A, Fouts J, et al. Adipose tissue, obesity and adipokines: role in cancer promotion. Horm Mol Biol Clin Inves- tig. 2015; 21(1): 57-74, doi: 10.1515/hmbci-2014-0037, indexed in Pubmed: 25781552

19. Page ST, Herbst KL, Amory JK, et al. Testosterone administration suppresses adiponectin levels in men. J Androl. 2005; 26(1): 85-92, indexed in Pubmed: 15611571.

20. Frederiksen L, Højlund K, Hougaard DM, et al. Testosterone therapy decreases subcutaneous fat and adiponectin in aging men. Eur J Endocrinol. 2012; 166(3): 469-476, doi: 10.1530/EJE-11-0565, indexed in Pubmed: 22190001.

21. Saad F, Aversa A, Isidori AM, et al. Onset of effects of testosterone treatment and time span until maximum effects are achieved. Eur J Endocrinol. 2011; 165(5): 675-685, doi: 10.1530/EJE-11-0221, indexed in Pubmed: 21753068. 